\title{
Challenges in communicating genetics: A public health approach
}

\author{
Muin J. Khoury, $M D, P h D^{1}$, James F. Thrasher, $M P H^{l}$, Wylie Burke, $M D, P h D^{2}$, Elizabeth A. Gettig, $M S^{l}$, \\ Fred Fridinger, $P h D^{3}$, and Richard Jackson, $M D, P h D^{4}$
}

With the entire human genome slated for sequencing soon, ${ }^{1}$ almost every day brings a new scientific discovery of a genetic variant that is associated with a specific disease. ${ }^{2}$ In the wake of these discoveries, the popular press has published numerous articles on how advances in genetic science will radically transform the practice of medicine. ${ }^{3-5}$ These portrayals of the impact of genetics are typified by a recent special issue of Time magazine ${ }^{3}$ with headlines reading: "Parenting: Designer Babies," "Genetic Screening: Good eggs, Bad eggs," and "Cursed by eugenics." Rarely, if ever, do these and other articles on genetics cover the public health implications of gene discovery.

The impact of genetic discoveries on public health practice is likely to be felt across all disease areas. For example, Shpilberg et al., ${ }^{6}$ state: "the sequencing of the human genome offers the greatest opportunity for epidemiology since John Snow discovered the Broad Street pump." This parallel between a seminal event in public health a century and a half ago and the current milieu of gene discovery has prompted the challenge of finding effective public health interventions based on geneticepidemiologic information. Public health professionals will increasingly use genetic information to more effectively target behavioral and environmental factors that lead to many diseases. ${ }^{7,8}$ Ensuring that these opportunities are well understood and supported requires communication with policy makers, health-care providers, other health professionals, and the public on the appropriate use of genetic information in disease prevention. ${ }^{9}$

This article is structured around a set of public health oriented communication themes and messages on genetics and disease prevention that provide a population perspective to the popular themes and messages promulgated by the media : 1) human diseases result from gene-environment interaction; 2) population research is needed to determine the clinical validity and utility of genetic testing; and 3) genetic information can be used to target interventions that improve health and prevent disease (see Table 1). These themes provide public

\footnotetext{
From the 'Office of Genetis and Discase Prevention, Notional Center for Entironmental Health, Centers for Disease Coutrol and Presention, Allanta, Georgia, the Department of Medicine. L'nuersity of Washington, Seattle. Washmgton: the 'Division of Nutrition and Physical Aitivity, National Cinter for Chronic Disease Prevention and Health Promotion. Atlanta. (jeorgia; and the "National Center for Fnirommental Health, Centers for Discase Control and Prevention, Allanta, Giorgia.

Dr. Khourv, Centers for Discuse Control and Prevention, Office of Genctics a Discase Pre vention, 4770 Buford Highway MS K2S. Atlanta, GA 30341

Reculed: February 25, 2000

Accepted: March 24, 2(m)
}

health responses to the concerns expressed in media coverage on genetics and may enable health professionals to reframe discussions of genetic advances. We hope that they will generate dialogue among medical, public health, communication professionals, and the general public in order to develop and test messages for public education campaigns.

\section{Human diseases result from gene-environment interaction}

Popular representations of genetics are often deterministic reinforcing a view of humans as a product of their genes, to the exclusion of nongenetic factors. ${ }^{10-12}$ Early discoveries of severe and often incurable conditions may have raised concerns about genetic determinism (e.g., Tay-Sachs disease, Huntington disease). Indeed, many of these disorders can be traced to a deficiency in the product of one gene that leads to a very high risk of developing some clinical disease. Insights into these single-gene diseases have been extremely important because, collectively, they make up approximately $5-10 \%$ of human disease. However, the role of common genetic variants (often called polymorphisms) in susceptibility to common diseases is increasingly understood. As more and more of these genetic variants are discovered, the scope of the public discussion of genetics needs to be broadened beyond single-gene disorders to include almost all human diseases. A useful framework upon which to build discussions about the integration of genetics into public health starts with the idea of gene-environment interaction.

We often tend to think about the spectrum of disease causation as ranging from completely genetic to completely environmental. A common way to summarize and present information about the causes of a specific condition is through a causal pie chart in which all of the causes add up to $100 \%$ of the disease. Common methods of genetic analysis (e.g., twin studies) are designed to partition the components of genetic and environmental contributions to disease. ${ }^{13}$ However, stating that a condition $\mathrm{X}$ is $40 \%$ genetic and $60 \%$ environmental sets up a misleading dichotomy between genes and the environment and obscures the fact that most if not all human disease results from the interaction between genetic susceptibility and environmental factors (broadly defined to include infectious, chemical, physical, nutritional, and behavioral factors). Even many of the classic single-gene disorders of metabolism result from a deficiency in a gene-produced enzyme that breaks down one or more chemicals in the diet. For example, phenylketonuria (PKU) results from a genetic variant that leads to deficient metabolism of the amino acid phenylalanine; in the 
Table 1

A public health approach to communicating genetics

\begin{tabular}{|c|c|c|}
\hline Themes & Examples of popular messages ${ }^{*}$ & Public health themes \\
\hline Role of genes in human disease & $\begin{array}{l}\text { Genetic disease or environmental disease } \\
\text { Nature vs. nurture } \\
\text { "Who has the good genes?" } \\
\text { "Good eggs, bad eggs" }\end{array}$ & $\begin{array}{l}\text { Human diseases result from gene-environment } \\
\text { interaction Nature AND nurture }\end{array}$ \\
\hline \multicolumn{3}{|l|}{ Nature vs. nurture } \\
\hline Advances in human genetics & $\begin{array}{l}\text { "Racing to map our DNA" } \\
\text { "Gene Hunters" }\end{array}$ & $\begin{array}{l}\text { Population research is needed to determine clinical } \\
\text { validity and utility of genetic tests }\end{array}$ \\
\hline Developing policies for disease prevention & $\begin{array}{l}\text { "Fixing the genes" (Gene therapy) } \\
\text { "Drugs by design" (Pharmacogenomics) } \\
\text { "Cursed by eugenics" (Genotypic prevention) }\end{array}$ & $\begin{array}{l}\text { Genetic information can be used to target interventions } \\
\text { that improve health \& prevent disease }\end{array}$ \\
\hline
\end{tabular}

*Quotes are headlines from Time magazine, January 11, 1999 special issue on the future of medicine.

presence of normal protein intake, phenylalanine accumulation occurs and is neurotoxic, but the disease can be prevented with a diet low in phenylalanine. The excessive build up of phenylalanine causes the disease, not the gene or dietary exposure by itself. ${ }^{14}$ Similarly, the so-called environmentally caused diseases are influenced by genetic susceptibility. For example, even though more than $90 \%$ of lung cancer is caused by cigarette smoking, only $10-15 \%$ of smokers will develop lung cancer, indicating the interaction of smoking with other factors including genetic ones. ${ }^{15}$ Everyone carries genetic variants that increase their susceptibility to some diseases, and, as a result, the same environmental factors will differently affect the development of disease.

If we accept the fundamental premise that variations in genetic make-up are associated with all human disease, there is no compelling reason to label a disease as either genetic or environmental. For example, one could think of hereditary hemochromatosis as an iron overload disorder that results from the interaction among iron intake, an inherited variation in iron transport, and iron loss. Similarly, breast cancer in some women could result from the interaction between inherited variations in the BRCA1 gene and yet-to-be-described factors, including other genes and modifiable behavioral or environmental risk factors. What is inherited is not the disease state per se, but rather the set of genetic variants that affect a dynamic balance between normal and pathologic processes. Disease is rarely an inevitable consequence of a particular genetic variation. Along the pathway to disease, the product of one gene interacts with the products of other genes as well as with other nongenetic factors.

\section{Population research is needed to determine the clinical validity and utility of genetic testing}

The announcement of gene discovery is often followed by scientific excitement, heightened public awareness, and commercial interest in developing and marketing genetic tests. It is easy to get caught up in this excitement and to envision the relevance of these discoveries to health care. The potential problem of doing this, however, is exemplified by the news coverage that followed the publication of a scientific article on familial colorectal cancer and an adenomatosis polyposis coli
(APC) genetic variant in Ashkenazi Jews. ${ }^{16}$ The news article declared "the good news is that scientists have developed a blood test, that can detect this genetic defect. The test is advisable for everyone in the Ashkenazim population, whether they have a family history of colon cancer or not." 17 This recommendation was given without recognizing that this study needed further confirmation and that the risks and benefits of finding out whether one carries the APC genetic variant are still unknown. In particular, it is not yet clear whether carriers of this gene variant require screening programs or treatments different from those offered to persons of average risk; thus a positive test result does not offer health care guidance and could result in adverse effects such as loss of access to insurance. The news coverage of this research finding reflects the mounting pressures for a rapid integration of gene discovery into clinical practice.

For most diseases, there is a large gap between the discovery of a gene and the safe and effective use of genetic information to prevent disease. A simple public health message is that gene discovery is only a beginning. Moving beyond gene discovery to relevant action in the health care system requires research activities in each of the core functions of public health ${ }^{18,19}:$ (1) assessment-including epidemiologic research to quantify the impact of a genetic variant and gene-environment interaction on community health; (2) policy development-including research to identify and analyze the economic, social, ethical, and psychological implications of advances in human genetics, and the information and communication needs of the general public; and (3) assurance-including health service delivery research to identify factors that influence the delivery, utilization, and quality of genetic tests and services. If genetics is not integrated into a public health research agenda, we may not be able to "translate" the numerous gene discoveries into meaningful population-based information that can be used to improve health and prevent disease. ${ }^{20}$ As part of this process, we need to anticipate that some genetic discoveries will lead to opportunities to improve public health whereas others will not. Translational research in each of the core areas of public health is a necessary step in this determination. As this research is done, public health professionals will be increasingly involved in monitoring and investigating the impact of genetic 
variation on the health of communities, developing policy on the appropriate use of genetic tests and services, ensuring the provision of appropriate services, and evaluating the health impact of using genetic information. ${ }^{19}$

Assessment of the health benefits of obtaining a genetic test is built upon clinical and population-based research from a variety of settings. Clinical research is often conducted in selected populations, such as hospital patients or extended families with multiply-affected members. Much of the current research to find disease-linked genes uses high-risk families or other family-based designs, as is exemplified by the successful use of large families to identify the Huntington disease gene ${ }^{21}$ and the breast/ovarian cancer genes.22 The results of clinical research conducted in high-risk families may not, however, be representative of what happens in the general population. Genetic or environmental factors may attenuate the association between the genetic variant and disease among those in the general population. Identifying the factors that reduce the likelihood of developing disease is critical for improved public health.

Ultimately, the utility of genetic information will depend on whether a genetic test can lead to a medical, behavioral, or environmental intervention that prevents disease and disability. However, the effectiveness of interventions will depend partly on a test's ability to discriminate between those who are likely to develop the disease and those who are not. Misclassification of an individual, and the consequences of intervention decisions that follow, can occur because of poor accuracy of the test (analytic validity) or because the genetic variant tested either has a low risk of disease (penetrance) or is associated with a small fraction of disease (etiologic heterogeneity). The latter two concepts refer to the clinical validity of a test. Analytic and clinical validity are discussed in detail in the final report of the NIH-DOE Task Force on Genetic Testing. ${ }^{23}$ To improve decision-making in genetic testing, it will be necessary to follow-up individuals who are tested and evaluate the effectiveness of ensuing interventions (clinical utility).

\section{Genetic information can be used to target interventions that improve health and prevent disease}

The media often report on the ethical issues surrounding the use of genetic technologies to produce children who are without genetic "flaws." Juengst ${ }^{24}$ has called "genotypic prevention" the interruption of genetic trait transmission from one generation to the next through reproductive counseling, carrier testing, prenatal diagnosis, and pregnancy termination. The legacy of the eugenics movement fuels concerns about the selective abortion of fetuses without the "best" set of genes, and about access to these technologies. Some have argued that public health agencies should play a role in ensuring an individual's or a couple's access to reproductive risk information, including prenatal diagnosis and genotypic prevention of severe or lethal conditions, such as Tay Sachs disease. ${ }^{25}$ For many couples, the availability of prenatal diagnosis provides a level of reassurance that permits them to proceed with childbearing they would otherwise forego, and thus supports their well-being, a goal encompassed within a broad definition of public health. Ensuring availability of and voluntary access to prenatal services, and evaluating the impact of these services would fall within the purview of public health practice..$^{25}$

When there are proven and cost-effective interventions to prevent disease and disability, the public heath community should take a more active role in promoting the use of genetic tests and services. The need for such public health-driven prevention is more clear-cut for adult-onset multifactorial conditions such as cancer and heart disease, than it is for early-onset, lethal single-gene conditions. Juengst calls this "phenotypic prevention" the prevention of disease, disability, or death among people with specific genotypes. ${ }^{24}$ In its recent strategic plan, ${ }^{8} \mathrm{CDC}$ endorsed the concept of phenotypic prevention as the strategy for public health-driven programs.

Media coverage of phenotypic prevention concentrates on the medical interventions of gene therapy and pharmacogenomics. Gene therapy refers to replacing the products of nonfunctional genes, ${ }^{26}$ and holds great promise for "fixing" many single-gene disorders ranging from cystic fibrosis to thalassemia. Inroads have even been made in the treatment of various cancers by manipulating the genes of malignant cells. Pharmacogenomics may also improve health by identifying genetic factors that contribute to drug metabolism. ${ }^{27}$ Researchers in this emerging field will be designing drugs to prevent adverse side effects caused by genetic susceptibility and to enhance therapeutic effectiveness. This approach could include tailoring drug regimens to an individual's genetic profile. Although these fields have not achieved any major breakthroughs, the progress that is expected in the next few years has generated much excitement.

Despite the excitement about new technologies such as gene therapy and pharmacogenomics, it is important to consider that public health interventions based on genetic information are just as likely, if not more likely, to impact disease prevention at the population level. The fact that most human diseases arise from gene-environment interactions leads to the potential for public health interventions on the environmental side. Indeed, many major successes in improving health stem from public health efforts to modify environments. CDC's recent list of the top public health achievements of the 20th century include vaccinations, smoking reduction, prenatal care, food safety, control of occupational exposures, infectious disease control, and water fluoridation. ${ }^{28}$ As we enter the posthuman genome project era in the new millennium, it is important to envision the role that environmental interventions could play.

Environmental interventions, medical treatment, diet modification, and behavior modification have already been developed for many single gene traits that confer a relatively high risk for disease. It is more difficult to devise such precise interventions for common and chronic diseases that have multiple causes. For instance, more than 270 risk factors have been identified for cardiovascular disease. ${ }^{29}$ With so many risk factors, the predictive power of any single risk factor for chronic disease is limited, ${ }^{30,31}$ as is the clinical relevance of these risk factors and their potential as a target for prevention efforts. 
However, genetic information could more adequately quantify an individual's susceptibility to disease, and, by doing so, could clarify the specific factors that interact with this susceptibility to produce disease. The ability to better characterize susceptibility to disease will go a long way toward providing better explanations of why "some vegetarians with 'acceptable' cholesterol levels suffer myocardial infarction in the 30's. Other individuals... seem to live forever despite personal stress, smoking, obesity, and poor adherence to a Heart Associationapproved diet." 32 The genetic information that is used to explain why such situations will also provide a guide to the most effective targeting of programs for medical, behavioral, and environmental risk reduction.

Genetic information may also provide guidance for targeted screening efforts. For instance, persons who have a first-degree relative with colorectal cancer have an increased risk and earlier onset of colorectal cancer, compared with persons without a family history. ${ }^{33}$ Early initiation of colorectal cancer screening in this group represents a public health opportunity. For a small subset of cases in which family history suggests high risk (multiply affected relatives, early age at onset), genetic testing may help determine the most effective recommendations around the frequency, method, and onset of screening.

A simple epidemiologic model shows how the predictive power of an environmental risk factor can dramatically increase if limited to persons who carry the particular susceptibility gene(s) with which this environmental factor interacts. Khoury and Wagener ${ }^{34}$ use an example of a disease with lifetime risk of $1 \%$, a susceptibility genotype prevalence of $1 \%$, and a risk factor prevalence of $10 \%$. They assume that the disease-causing effect of the risk factor is confined to persons with a susceptibility genotype, but within the general population, the relative risk associated with exposure to the environmental factor is 2 . Under these conditions, the risk factor would have a positive predictive value of $1.8 \%$. However, when the analysis is confined to those who carry the susceptibility genotype, the positive predictive value of the risk factor increases to $91.8 \%$. If this risk factor is modifiable, such as diet, then genetic testing could identify persons who should avoid exposure to this risk factor. This model sketches the framework of primary prevention in the $21^{\text {st }}$ century: the identification and interruption of environmental factors that lead to disease among persons with susceptibility genotypes.

In communicating the impact of genetics on treatment and prevention, messages about gene therapy and pharmacogenomics need to be complemented with messages about the potential for behavioral and environmental interventions based on genetic information. Such messages could lead to a better appreciation of how behaviors can reduce disease risk. Risk reduction in the face of genetic susceptibility is complex. It will require additional research in risk communication and the behavioral sciences to understand how to safely and effectively bring about the changes needed to improve health among those who have genetic susceptibility. Until such interventions are available for any given genetic trait, identification of genetic susceptibility may do more harm than good.

\section{CONCLUSIONS}

We have presented three simple public health themes that can provide a basis for developing public health messages about genetics and disease prevention to various audiences: (1) human diseases result from gene-environment interaction; (2) population research is needed to determine the clinical validity and utility of genetic testing; (3) genetic information can be used to target interventions that improve health and prevent disease. These messages underscore how knowledge of genetics presents an opportunity to prevent disease, and in showing these benefits, they aim to reduce fear over the misuse of genetic information. Qualitative and quantitative research can help determine the best means of communicating about genetics and disease prevention. However, we offer this commentary as a starting point because of our concern that the next few years will yield a myriad of genomic data and an inability to act because of ethical and social concerns. We hope that these messages can be used to initiate discussions on how scientific advances in genetics will be translated into public health action in the $21^{\text {st }}$ century.

\section{References}

1. Collins FS. Shattuck lecture: Medical and societal consequences of the Human Genome Project. N Engl J Med 1999;341:28-37.

2. Centers for Disease Control and Prevention. Office of Genetics and Disease Prevention weekly update. Available at: http://www.cdc.gov/genetics/update/current.htm.

3. The future of medicine: How genetic engineering will change us in the next century. Time 1999:153(special issue):42-92.

4. Begley S. Screening for genes: Matching medications to your genetic heritage. Newsweek Online. February 8,1999 . Available at: http://newsweek.com/nw-srv/issue/ 06_99a/printed/us/st/sc0106_1.htm.

5. Shreeve J. Secrets of the Gene. National Geographic Online. October 1999. Available at: http://www.nationalgeographic.com/ngm/9910/hilights.html\#c.

6. Shpilberg O, Dorman JS, Ferrell RE, Trucco M, Shahar A, Kuller LH. The next stage: Molecular epidemiology. J Clin Epidemiol 1997;50:633-638.

7. Zimmern RL. The human genome project: A false dawn? BMJ 1999;319:1282.

8. Centers for Disease Control and Prevention. Translating advances in human genetics into public health action: A strategic plan. Available at: http://www.cdc.gov/ genetics/Strategic.html.

9. Khoury MI and the Genetics working group. From genes to public health: Applications of genetics in disease prevention [Commentary]. Am J Public Health 1996;86: $1717-1722$.

10. Nelkin D, Lindee MS. The DNA mystique: The gene as cultural icon. New York: WH Freeman, 1995.

11. Hubbard R, Wald E. Exploding the gene myth. Boston: Beacon Press, 1993.

12. van Dijck J. Imagination: Popular images of genetics. New York: New York University Press, 1998.

13. Khoury MJ, Beaty TH, Cohen BH. Fundamentals of genetic epidemiology. New York: Oxford University Press, 1993.

14. Allen DB, Farell PM. Newborn screening: Principles and practice. Adv Pediatr 1996; 43:231-270.

15. Spitz MR, Wei Q, Li G. Genetic susceptibility to tobacco carcinogenesis. Cancer Invest 1999;17:645-659.

16. Laken SI, Petersen GM, Gruber SB, Oddoux C, Ostrer H, Giardiello FM, Hamilton SR, Hampel H, Markowitz A, Klimstra D, Jhanwar S, Winawer S, Offit K, Luce MC, Kinzler KW, Vogelstein B. Familial colorectal cancer in Ashkenazim due to hypermutable tract in APC. Nat Genet 1997;17:79-83.

17. Cancer Research Foundation of America. Available at: http://www.preventcancer org/.

18. Institute of Medicine. The future of public health. Washington, DC: National Academy Press, 1988.

19. Khoury MJ, Burke W, Thomson E, editors. Genetics and public health in the 21st century: Using genetic information to improve health and prevent disease. New York: Oxford University Press [In press].

20. Khoury MJ. Human genome epidemiology (HuGE): Translating advances in human genetics into population-based data for medicine and public health. Genet Med 1999;1:71-74. 


\section{Khoury et al.}

21. Reddy PH, Williams M, Tagle DA. Recent advances in understanding the pathogenesis of Huntington's disease. Trends Neurosci 1999;22:248-255.

22. Neuhausen SL, Ostrander EA. Mutation testing of early-onset breast cancer genes BRCA1 and BRCA2. Genet Test 1997;1:75-83.

23. Holtzman NA, Watson MS, editors. Promoting safe and effective genetic testing in the United States: Final report of the task force on genetic testing. 1997. Available at: http://www.nhgri.nih.gov/ELSI/TFGT_final/.

24. Juengst ET. "Prevention" and the goals of genetic medicine. Hum Gene Ther 1995; 6:1595-1605.

25. Clayton EW. What should be the role of public health in newborn screening and prenatal diagnosis? Am J Prev Med 1999;16:111-115.

26. Smith AE. Gene therapy: Where are we? Lancet 1999;354(Suppl 1):1-4.

27. Housman D, Ledley FD. Why pharmacogenomics? Why now? Nat Biotechnol 1998; 16:492-493.

28. Centers for Disease Control and Prevention. Ten great public health achievements: United States, 1900-1999. Morb Mortal Wkly Rep 1999:48:241-243.
29. Stehbens WE. Causality in medical science with particular reference to heart disease and atherosclerosis. Perspect Biol Med 1992;36:97-119.

30. Baron J. The clinical utility of risk factor data. J Clin Epidemiol 1989;42:1013-1020.

31. Khoury MJ, Newill CA, Chase GA. Epidemiologic evaluation of screening for risk factors: Application to genetic screening. Am J Public Health 1985;75:12041208.

32. Hegele RA. Gene-environment interactions in atherosclerosis. Mol Cell Biochem 1992;113:177-186.

33. Winawer S, Fletcher R, Miller L, Godlee F, Stolar MH, Mulrow CD, Woolf SH, Glick SN, Ganiats TG, Bond JH, Rosen L, Zapka JG, Olsen SJ, Giardiello FM, Sisk JE, Van Antwerp R, Brown-Davis C, Marciniak DA, Mayer RJ. Colorectal cancer screening: Clinical guidelines and rationale. Gastroenterology 1997;112:594-642.

34. Khoury MJ, Wagener DK. An epidemiologic evaluation of the use of genetics to improve the predictive value of disease risk factors. Am J Hum Genet 1995;56:835844. 